\section{OPEN ACCESS}

Edited by:

Matteo Bellone,

San Raffaele Hospital (IRCCS), Italy

Reviewed by:

Eric Tartour

Hôpital Européen Georges-Pompidou (HEGP), France

Xiangjiao Meng,

Shandong Cancer Hospital, China

*Correspondence:

Francesco Sabbatino

fsabbatino@unisa.it

${ }^{\dagger}$ These authors have contributed equally to this work

Specialty section:

This article was submitted to

Cancer Immunity and

Immunotherapy,

a section of the journal

Frontiers in Immunology

Received: 12 May 2020 Accepted: 15 September 2020 Published: 29 September 2020

Citation:

Sabbatino F, Scognamiglio G, Liguori L, Marra A, Anniciello AM,

Polcaro G, Dal Col J, Caputo A,

Peluso AL, Botti G, Zeppa P,

Ferrone $S$ and Pepe $S$ (2020)

Peritumoral Immune Infiltrate

as a Prognostic Biomarker

in Thin Melanoma.

Front. Immunol. 11:561390.

doi: 10.3389/fimmu.2020.561390

\title{
Peritumoral Immune Infiltrate as a Prognostic Biomarker in Thin Melanoma
}

\begin{abstract}
Francesco Sabbatino ${ }^{1,2 * t}$, Giosuè Scognamiglio ${ }^{3 \dagger}$, Luigi Liguori ${ }^{4}$, Antonio Marra ${ }^{5}$, Anna Maria Anniciello ${ }^{3}$, Giovanna Polcaro ${ }^{1}$, Jessica Dal Col ${ }^{1}$, Alessandro Caputo ${ }^{1,6}$, Anna Lucia Peluso ${ }^{1,6}$, Gerardo Botti ${ }^{7}$, Pio Zeppa ${ }^{1,6}$, Soldano Ferrone ${ }^{8}$ and Stefano Pepe ${ }^{1,2}$

1 Department of Medicine, Surgery and Dentistry "Scuola Medica Salernitana", University of Salerno, Baronissi, Italy, 2 Oncology Unit, San Giovanni di Dio e Ruggi D'Aragona University Hospital, Salerno, Italy, ${ }^{3}$ Pathology Unit, Istituto Nazionale Tumori, IRCSS, "Fondazione G. Pascale", Naples, Italy, ${ }^{4}$ Department of Clinical Medicine and Surgery, University of Naples "Federico II", Naples, Italy, ${ }^{5}$ Division of Early Drug Development for Innovative Therapies, IEO, European Institute of Oncology, Milan, Italy, ${ }^{6}$ Pathology Unit, San Giovanni di Dio e Ruggi D'Aragona University Hospital, Salerno, Italy, ${ }^{7}$ Scientific Direction, Istituto Nazionale Tumori-IRCCS-Fondazione G. Pascale, Naples, Italy, ${ }^{8}$ Division of Surgical Oncology, Department of Surgery, Massachusetts General Hospital, Harvard Medical School, Boston, MA, United States
\end{abstract}

Thin melanomas are tumors less than $1 \mathrm{~mm}$ thick according to Breslow classification. Their prognosis is in most cases excellent. However, a small subset of these tumors relapses. These clinical findings emphasize the need of novel prognostic biomarkers to identify this subset of tumors. Characterization of tumor immune microenvironment (TIME) is currently investigated as a prognostic and predictive biomarker for cancer immunotherapy in several solid tumors including melanoma. Here, taking into account the limited availability of tumor tissues, by characterizing some of the characteristics of TIME such as number of infiltrating lymphocytes, HLA class I antigen and PD-L1 expression, we show that number of infiltrating CD8+ and FOXP3+ T cells as well as CD8+/FOXP3+ T cell ratio can represent a useful prognostic biomarker in thin melanoma. Although further investigations in a larger patient cohort are needed, these findings have potential clinical significance since they can be used to define subgroups of thin melanoma patients who have a worse prognosis and might need different treatment modalities.

Keywords: thin melanoma, tumor-infiltrating lymphocytes, CD4, CD8, time, human leukocyte antigen class I antigens, programmed death-ligand 1, prognosis

\section{INTRODUCTION}

The incidence of skin melanoma is increasing worldwide with 60.7 per 100,000 patients dead for this type of cancer in 2018. (1). Considerable disparities in terms of survival exist between loco-regional and metastatic melanoma with 5 -year relative survival rates of $64-98 \%$ and $20 \%$, respectively (2), although recent advances in targeted therapy and immunotherapy have dramatically improved metastatic melanoma patients' overall survival. Hopefully, most of new melanomas are diagnosed at an early stage and up to one third of new cases are detected as in-situ lesions (2). According to TNM classification, 5- and 10-year survival rates are different within the $\mathrm{T}$ subgroups, ranging from 97 to 
93\% and from 53 to $39 \%$ for patients with T1 (Breslow depth $<1 \mathrm{~mm}$ ) - usually termed thin melanoma-and T4 melanomas, respectively (3). In order to better define thin melanoma prognosis, the presence of aggressive features such as depth higher than $0.75 / 0.85 \mathrm{~mm}$ and presence of ulceration are currently utilized as major prognostic biomarkers $(4,5)$. In addition, other characteristics of thin melanoma, including lymphovascular invasion and tumor regression, have been also associated with a higher risk of recurrence (6). Nevertheless, some thin melanomas with such favorable prognostic features, develop local or distant metastases. These clinical findings emphasize the need to integrate more effective prognostic biomarkers in those clinicopathological characteristics. Several lines of evidence have highlighted the crucial role of tumor immune microenvironment (TIME) in melanoma biology $(7,8)$. Overall the presence of tumor-infiltrating lymphocytes (TILs) in melanomas has been associated with a better patient prognosis, regardless of other clinicopathological characteristics (9-15), although the presence of TILs in improving melanoma prognosis remains controversial (16). In addition, both characterization of the tumor immune infiltrate by CD8+ and regulatory $\mathrm{CD} 4+\mathrm{T}$ cells and detection of tumor immune escape mechanisms, including programmed death-ligand 1 (PD-L1) upregulation and human leukocyte antigen (HLA) class I downregulation on cancer and/or immune cells, have been shown to better define the melanoma disease course (17-23). However, scant data about the prognostic role of TIME characteristics in thin melanoma subgroups are available so far. Therefore, the aim of our study was to analyze some of the TIME characteristics in a cohort of patients with surgically resected thin melanoma and to evaluate their potential clinical significance.

\section{MATERIALS AND METHODS}

\section{Patients and Tumor Tissues}

Formalin-fixed paraffin-embedded (FFPE) tumor specimens were obtained from patients with surgically resected thin melanoma (depth $\leq 1 \mathrm{~mm}$ ) followed at "San Giovanni di Dio e Ruggi D’Aragona” University Hospital between 2010 and 2020. Patient selection was performed based on tumor tissue and clinical record availability. All samples were from Caucasian patients. Patients were consented for tissue acquisition per institutional review board-approved protocol. All patients signed an informed consent. Diagnosis of melanoma was confirmed by an independent, skin cancer-dedicated pathologist (PZ). Presence of tumor cells in FFPE was monitored by hematoxylin and eosin staining. Melanomas were staged according to the $8^{\text {th }}$ Edition of the American Joint Committee on Cancer (AJCC) classification system. Sentinel lymph node biopsy was performed in all patients if melanoma lesion was $>0.75 \mathrm{~mm}$ thick or in presence of ulceration. Patient demographic (age and gender), pathological (TNM stage, Breslow depth, tumor localization, presence of ulceration and/ or regression, number of mitosis $/ \mathrm{mm}^{2}$, presence of TILs) and disease free survival (DFS) data were retrieved from clinical records. Presence of regression was defined as partial, segmental or complete replacement of melanoma cells with a variable host response including dense mononuclear infiltrate, melanophages and/or dermal fibrosis accompanied by increased dermal vascularity, with variable epidermal attenuation (24-26). In addition to further characterize the prognostic role of tumor regression a $10 \%$ cut off of regression extension was also adopted as previously reported (27).

\section{Monoclonal Antibodies}

The monoclonal antibodies (mAbs) HCA2, which recognizes $\beta 2 \mathrm{~m}$-free HLA-A (excluding -A24), -B7301, and -G heavy chains $(28,29)$, and HC10, which recognizes $\beta 2 \mathrm{~m}$-free HLA-A3, -A10, -A28, -A29, -A30, -A31, -A32, -A33, and all $\beta 2 \mathrm{~m}$-free -HLA-B (excluding -B5702, -B5804, and -B73) and -HLA-C heavy chains $(28-30)$, were developed and characterized as previously described. mAbs were purified from ascitic fluid by affinity chromatography on a Protein G column. Purity and activity of $\mathrm{mAb}$ preparations were monitored by SDS-PAGE and by specific reactivity with the corresponding antigen in binding assays and Western blotting. The CD8-specific mAb C8/144B (Dako), the FOXP3-specific mAb D2W8E (Cell Signaling), the Granzyme B (GRZ-B)-specific mAb ab4059 (Abcam) and the PD-L1-specific $\mathrm{mAb}$ E1L3N (Cell Signaling) were purchased from the indicated companies. The mouse mAb E7Q5L (IgG2b) was used as an isotype control for HCA2 and $\mathrm{HC} 10$ staining. The rabbit mAb DA1E (IgG) was used as an isotype control for PD-L1 staining.

\section{Immunohistochemical Staining}

FFPE tissue sections ( $4 \mu \mathrm{m}$ ) from melanoma tumor samples were used as substrates in immunohistochemical (IHC) reactions. IHC staining with a pool of mAb HCA2 and HC10 (in a 1:1 ratio) was performed and scored as described previously (31-33). The staining with C8/144B, D2W8E, ab4059 and E1L3N mAbs was performed on BOND automated IHC Stainer (Leica). The double staining with C8/144B and D2W8E mAbs was performed utilizing the ChromoPlex 1 Dual Detection kit (Leica) while the staining with ab4059 and E1L3N mAbs was performed utilizing 3,3' diaminobenzidine (DAB) chromogen (Dako). Staining intensity and percentage of stained tumor cells in each lesion were reviewed and enumerated by two experienced pathologists (AA and PZ) who had no knowledge of the patients' characteristics and clinical outcomes. Staining with CD8-, FOXP3-, GRZ-B- and PD-L1-specific mAbs was performed according to the manufacturers' instructions. Staining with CD8-, FOXP3-, GRZ-B- and PD-L1-specific mAbs was scored by counting the number of stained cells in four high-powered fields of melanoma lesions. For CD8-, FOXP3-, GRZ-B- scoring both peritumoral and intratumoral positive cells were counted. Peritumoral positive cells were defined as cells distributed along the stromal-tumor interface at tumor edge in dermis. Intratumoral positive cells were defined as cells completely surrounded the neoplastic cells. For scoring of PD-L1 staining, only tumor samples demonstrating cell membrane staining were considered positive. PD-L1 expression was evaluated only on tumor cells. 


\section{Statistical Analysis}

Statistical analysis was performed with the Stata Statistical Software, Version 13.0 (StataCorp,LP). Correlation of HLA class $\mathrm{I}$ antigen and PD-L1 expression with the number of $\mathrm{CD} 8+$, FOXP3+ and GRZ-B+ T cells was analyzed by Spearman rank correlation test. Correlation of PD-L1 expression with HLA class I antigen expression was analyzed by Fisher exact test. Differences in the expression levels of variables according to histopathologic and clinical characteristics were analyzed using the Mann-Whitney U test or the Kruskal-Wallis rank test. Disease-free survival (DFS) was calculated using the Kaplan-Meier method. Time was defined as the interval between the date of diagnosis and the date of disease recurrence (event) or that of last follow-up visit (censored). The log-rank test was used for screening the potential prognostic factors in relation to patients' survival. $\mathrm{p}<0.05$ was considered to be statistically significant. All tests used were two-tailed.

\section{RESULTS}

\section{Patient Characteristics}

Thirty-one patients were included in the study. Patient and tumor characteristics are summarized in Table 1. Median age was 56.4 years (range, 30-78). Eighteen patients (58.1\%) were female. Primary tumor localization was head/neck, limbs and trunk in $16.1,38.7$, and $38.7 \%$ of patients, respectively. The mean

TABLE 1 | Patient and tumor characteristics.

\begin{tabular}{|c|c|}
\hline Age & $56.4(30-78)$ \\
\hline \multicolumn{2}{|l|}{ Gender } \\
\hline Male & $13(41.9 \%)$ \\
\hline Female & $18(58.1 \%)$ \\
\hline \multicolumn{2}{|l|}{ Anatomic site } \\
\hline Head/neck & $5(16.1 \%)$ \\
\hline Limbs & $12(38.7 \%)$ \\
\hline Trunk & $12(38.7 \%)$ \\
\hline Not evaluable & 2 (6.5\%) \\
\hline Breslow depth & $0.4 \mathrm{~mm}(0.1-1.0)$ \\
\hline \multicolumn{2}{|l|}{ Ulceration } \\
\hline No & $28(90.3 \%)$ \\
\hline Yes & $3(9.7 \%)$ \\
\hline \multicolumn{2}{|l|}{ Regression } \\
\hline No & $2(6.5 \%)$ \\
\hline Yes & $20(64.5 \%)$ \\
\hline Not evaluable & 9 (29.0\%) \\
\hline \multicolumn{2}{|c|}{ Regression at $10 \%$ cut off } \\
\hline No & 9 (29.0\%) \\
\hline Yes & $13(41.9 \%)$ \\
\hline Not evaluable & 9 (29.0\%) \\
\hline \multicolumn{2}{|l|}{$\mathrm{TNM}^{\dagger}$} \\
\hline T1a & $23(74.2 \%)$ \\
\hline T1b & $8(25.8 \%)$ \\
\hline Mitosis $^{\ddagger}$ & $1.3(0-4.0)$ \\
\hline \multicolumn{2}{|c|}{ Tumor-infiltrating lymphocytes } \\
\hline Absent & 9 (29.0\%) \\
\hline Present & $13(42.0 \%)$ \\
\hline Not evaluable & 9 (29.0\%) \\
\hline
\end{tabular}

${ }^{+}$Staging according to the $8^{\text {th }}$ Edition of AJCC melanoma classification.

${ }^{\ddagger}$ Number of mitosis per square millimeter.
Breslow depth was $0.4 \mathrm{~mm}(0.1-1.0 \mathrm{~mm})$. Ulceration was present in $3(9.7 \%)$ out of the 31 patients investigated. Regression was present in $64.5 \%$ of the samples analyzed. Adopting a $10 \%$ cut off of extension, regression was present in $41.9 \%$ of sample analyzed. Twenty-three melanomas were classified as T1a (74.2\%) and 8 as T1b (25.8\%). The mean number of mitosis was $1.3 \mathrm{~mm}^{2}(0.0$ 4.0). TILs were present in 13 melanomas (42.0\%), defined as absent in 9 (29.0\%) and not reported in 9 (29.0\%). Metastases were not detected in all sentinel lymph node biopsies analyzed. At a median follow up of 92.0 months (20.0-105.0 months), the median DFS was not reached (Figure 1). Four (12.9\%) out of the 31 patients investigated developed a distant recurrence during the follow up.

\section{Correlation Between Clinical and Pathological Characteristics in Thin Melanomas}

Breslow depth positively correlated with the presence of ulceration $(\mathrm{p}=0.022)$. Ulcerated melanomas had an increased depth as compared to that of non-ulcerated (mean 0.92 versus $0.35 \mathrm{~mm}$; Figure 2A). In addition, Breslow depth positively correlated with the number of mitosis (Spearman's rho 0.5004, $\mathrm{p}=0.021$ ). Lastly, less than $10 \%$ of regression positively correlated with high Breslow (mean 0.82 versus $0.32 \mathrm{~mm} \mathrm{p}=0.0016$ ) and presence of ulceration ( $\mathrm{p}=0.055)$ (Figure 2B).

\section{Correlation of Immune Cell Infiltrate With Clinicopathological Characteristics of Thin Melanoma Tumors}

Representative IHC staining of CD8+, FOXP3+ and GRZ-B+ T cells is shown in Figures $\mathbf{3 A}$, B. The number of peritumoral CD8+ and GRZ-B+ T cells ranged from 4 to 89 (mean 48.3) and from 0 to 12 (mean 4.5), respectively. The number of intratumoral CD8+ and GRZ-B+ T cells ranged from 1 to 14 (mean 7.6) and from 0 to 2 (mean 0.58), respectively. On the other hand, the number of peritumoral and intratumoral FOXP3 + T cells ranged from 0 to 87 (mean 19.4) and from 0 to 13 (mean 3.0 ), respectively. CD8+/FOXP3+ T cell ratio ranged from 0.6 to 68.0 (mean 9.2). The number of peritumoral CD8+ T cells was positively correlated with number of intratumoral CD8+ T cells (Spearman's rho $=0.9892 ; \mathrm{p}<0.0001$ ). The number of peritumoral FOXP3 + T cells was positively correlated with number of intratumoral FOXP3 + T cells (Spearman's rho=0.9472; $\mathrm{p}<0.0001)$. The number of peritumoral and intratumoral CD8+ $\mathrm{T}$ cells was positively correlated with the number of peritumoral (Spearman's rho $=0.40004 ; \mathrm{p}=0.031$ ) and intratumoral (Spearman's rho $=0.43 ; \mathrm{p}=0.019)$ FOXP3 + T cells, respectively.

Representative IHC staining of HLA class I antigen expression by thin melanoma cells is shown in Figures $3 \mathbf{C}, \mathbf{D}$. HLA class I antigen expression was down-regulated in 5 (16.1\%) tumor samples but was within normal ranges in the remaining 24 (77.4\%). HLA class I antigen expression ranged from 0 to 70 (mean 28.7).

Melanomas localized to head/neck and trunk were associated with a higher level of TILs as compared to those to limbs $(\mathrm{p}=0.017)$. In addition, melanomas of limbs expressed a higher 
HLA class I antigen level as compared to those localized to trunk and to head and neck (median 40.8, 25.5 and 6.0, respectively; $\mathrm{p}=0.003$ ) (Figure 4A). Presence of TILs positively correlated with presence of more than $10 \%$ of regression extension $(\mathrm{p}=0.020)$.

The number of peritumoral and intratumoral FOXP3 $+\mathrm{T}$ cells in dermis was positively correlated with $\mathrm{T}$ stage subgroups (sec. TNM, AJCC $8^{\text {th }}$ Edition) (peritumoral $\mathrm{p}=0.015$; Figure 4B) (intratumoral $\mathrm{p}=0.021$; Figure $4 \mathrm{C}$ ). In addition, ulcerated tumors had a lower number of peritumoral GRZ-B+ T cells as compared to that of non-ulcerated tumors ( $p=0.09$; Figure 4D) and tumors with less than $10 \%$ of regression had a higher number of peritumoral FOXP3 $+\mathrm{T}$ cells as compared to that of more than $10 \%$ ( $p=0.08$; Figure $4 \mathrm{E})$. Lastly, CD8+/FOXP3+ T cell ratio negatively correlated with $\mathrm{T}$ stage subgroups (sec. TNM, AJCC $8^{\text {th }}$ Edition) ( $\mathrm{p}=0.041$; Figure 4F).

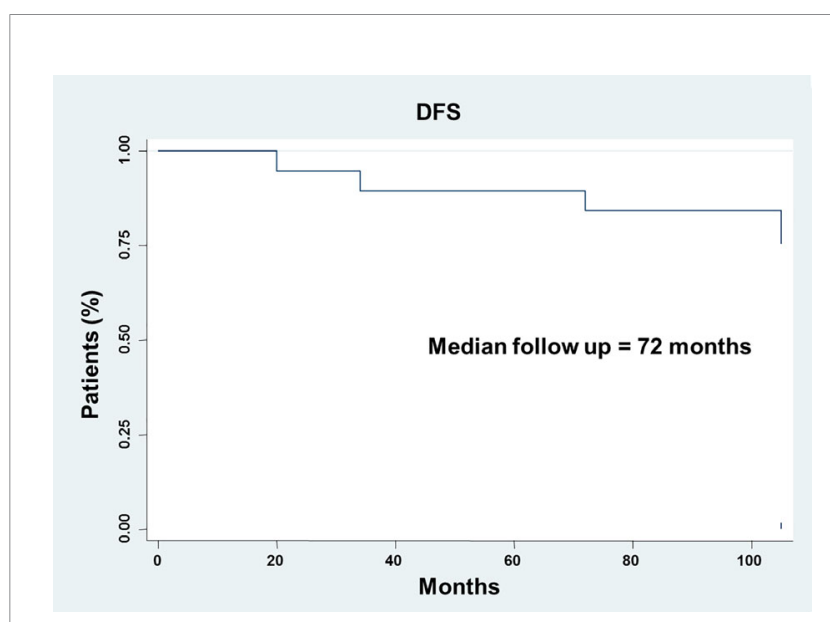

FIGURE 1 Analysis of the disease-free survival (DFS) in thin melanoma. DFS analysis was analyzed using the Kaplan-Meier method.

\section{PD-L1 Expression in Thin Melanomas and Its Interaction With Immune Infiltrate}

Representative IHC staining of PD-L1 expression by thin melanoma cells is shown in Figures 3E, F. PD-L1 expression was detected in 10 $(32.3 \%)$ out of 31 samples analyzed. The mean number of PD-L1+ cells was 3.29 per high powered field (0.0-25.0). No significant correlations were found between PD-L1 expression and the other clinicopathological characteristics of the samples analyzed as well as between PD-L1 expression and immune infiltrate.

\section{Correlation of TIME and Clinicopathological Characteristics With DFS}

At univariate analysis, age $(\mathrm{p}=0.005)$, Breslow depth $(\mathrm{p}=0.005)$, presence of ulceration $(\mathrm{p}<0.001)$, number of mitosis ( $\mathrm{p}=0.026)$, less than $10 \%$ of regression extension $(\mathrm{p}=0.08)$ as well as number of peritumoral FOXP3 + T cells (peritumoral $\mathrm{p}=0.006$ ) were negatively correlated to DFS. In contrast, number of CD8+ T cells (peritumoral $\mathrm{p}=0.034$; intratumoral $\mathrm{p}=0.005)$ and $\mathrm{CD} 8+/ \mathrm{FOXP} 3+\mathrm{T}$ cell ratio $(\mathrm{p}=0.022)$ were positively correlated to DFS (Figure 5).

\section{DISCUSSION}

Patients with thin melanoma have an excellent prognosis with 10 -year survival outcome ranging from 85 to $99 \%$ (3). For thin melanoma as well as for thicker melanoma, presence of ulceration, Breslow depth, mitotic rate, lymphovascular invasion and presence of regression are the most relevant prognostic biomarkers (4-6). However, so far, about $10 \%$ of surgically removed thin melanomas relapse. Informative biomarkers are needed to improve the stratification of patient prognosis and to design novel therapeutic strategies to prevent tumor relapse in this setting. In the present study, analysis of patient prognosis shows that ulceration, Breslow depth, mitotic rate and less than $10 \%$ of regression extension significantly
A

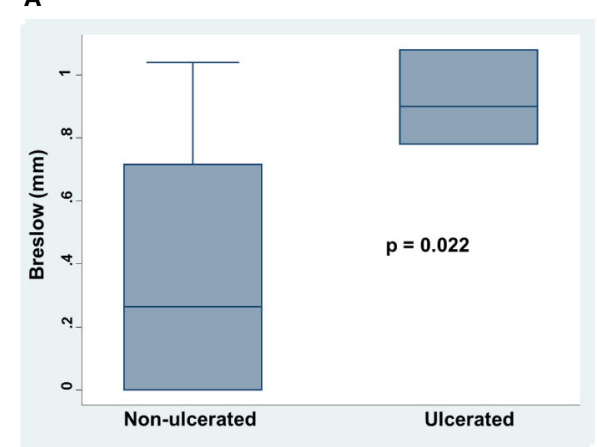

B

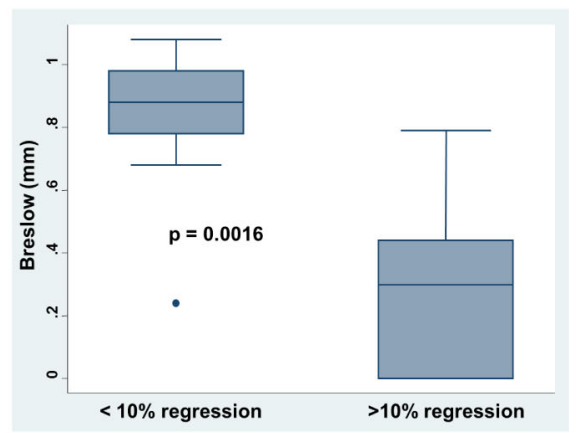

FIGURE 2 | Correlation between Breslow depth, presence of ulceration and tumor regression in thin melanoma. (A) Presence or absence of ulceration was correlated to Breslow depth by Mann-Whitney $U$ test. (B) Presence or absence of regression at 10\% cut off of extension was correlated to Breslow depth by MannWhitney $U$ test. On each box, the central mark is the median, the edges of the box are the $25^{\text {th }}$ and $75^{\text {th }}$ percentiles, the whiskers extend to the most extreme data points note considered outliers, and outliers are plotted individually. $p$ was considered significant if $<0.05$. 


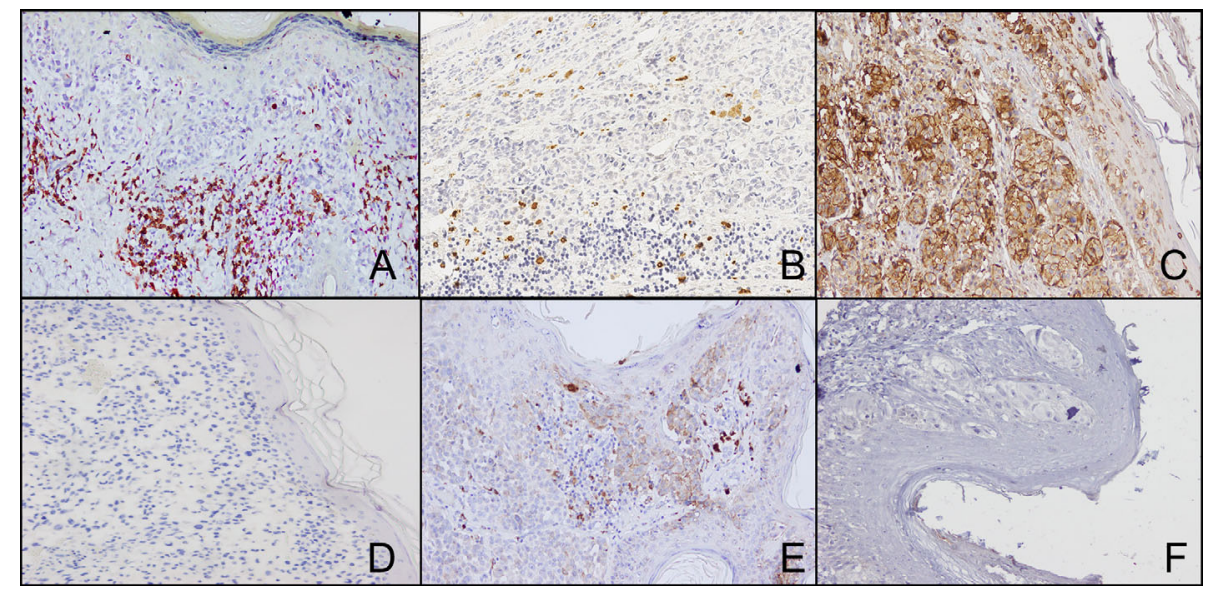

FIGURE 3 | Representative staining patterns of formalin-fixed, paraffin-embedded thin melanoma lesions with CD8- (A), FOXP3- (A), GRZ-B- (B), HLA class I antigen- (C) and PD-L1- (E) specific mAbs. Double IHC staining was performed utilizing CD8- (brown cells) and FOXP3- (red cells) specific mAbs (A). For HLA class I antigen detection tissue sections were IHC stained with a pool of mouse HLA-A-specific mAb HCA2 and HLA-B/C-specific mAb HC10 (ratio, 1:1). mAbs E7Q5L (IgG2b) and DA1E (IgG) were used as isotype controls for HLA class I antigen (D) and PD-L1 (F) staining, respectively. Magnification is 200X.

correlate with DFS in thin melanoma. In addition, a high Breslow depth positively correlates with a high number of mitosis, presence of ulceration and less than $10 \%$ of regression extension. By corroborating the information in the literature $(27,34,35)$ these results validate the representativeness of patient population analyzed in spite of its limited number.

In a recent study, Dessinioti et al. showed that nodular melanomas are associated with a poor prognosis in $\mathrm{T} 1$ stage subgroup as compared to that of superficial spreading melanomas (36). We were not able to provide this type of information since in our medical records, melanoma subtypes were not specified. Lundgren et al. demonstrated that a high expression of Kin of IRRE protein (KIRREL) is significantly associated with several unfavourable clinicopathological characteristics, including high Clark level and Breslow depth, presence of ulceration, advanced clinical stage and high mitotic rate in thin melanoma (37). The results of our study suggest that some of TIME characteristics might be useful prognostic biomarkers in patients with thin melanoma.

TIME characteristics are currently investigated as a prognostic and predictive biomarker for cancer immunotherapy in several types of solid cancers including melanoma (38). They play a major role in the host immune response to tumor antigens expressed on melanoma cells $(7,39)$. The crucial role of host immune response in melanoma is confirmed by the clinical efficacy of immune checkpoint inhibitor-based immunotherapy in this type of tumor (40). Indeed, treatment with anti-Cytotoxic T-Lymphocyte Antigen 4 and anti-Programmed cell Death 1 have dramatically changed the prognosis of melanoma patients (41-45). In this study, because of the limited availability of thin melanoma tissues we could not analyze multiple marker expression in order to fully characterize melanoma thin TIME. We focused our analysis on the characterization of TILs as a marker of host immune response to tumor antigens and HLA class I antigen down-regulation and PDL1 expression as mechanisms of immune escape by malignant cells.
TILs have been shown to play a favorable prognostic role in melanoma $(9-15,46,47)$ as their presence correlates with both Breslow depth and 10 year survival (48). However, the association of TILs with an improved prognosis in melanoma remains controversial. In addition, the impact of different components of TILs on melanoma's characteristics and prognosis is still under investigation $(18,21,22)$. In a recent meta-analysis Fu et al. have confirmed the favorable prognostic role of the $\mathrm{CD} 3+, \mathrm{CD} 4+, \mathrm{CD} 8+$ TILs in melanoma patients' overall survival as well as the association between TIL presence and improved overall survival (49). In the present study characterization of some TIME features has demonstrated that both numbers of peritumoral and intratumoral FOXP3+ and CD8+ $\mathrm{T}$ cells as well as their ratio might be useful prognostic biomarkers in thin melanomas. Specifically, either a low number of peritumoral or intratumoral CD8+ T cells and a high number of peritumoral FOXP3 $+\mathrm{T}$ cells negatively correlate with DFS. Our findings, in thin melanomas, are in line with the previous reports available in the literature for melanoma tumors. De Panfilis et al. demonstrated that number of FOXP3+ lymphocytes is higher in late stage melanoma as compared to that in early stage (17). Miracco et al. demonstrated that a high number of both FOXP3 + and CD25+ T cells in primary tumors correlates with a high rate of tumor relapse in melanoma (50). On the other hand, a high number of TCF7/CD8+ $\mathrm{T}$ cells in melanoma tumors has been associated with clinical responses to immunotherapy $(51,52)$. Furthermore tissue-resident memory CD8+ T cells play a crucial role in the surveillance of subclinical melanoma (23). In our study the number of CD8+ $\mathrm{T}$ cells positively correlates with the number of FOXP3 $+\mathrm{T}$ cells. In addition, when both CD8+ $\mathrm{T}$ cells and FOXP3 $+\mathrm{T}$ cells are present in a tumor, they are spatially very close. These findings suggest a potential interaction between $\mathrm{CD} 8+$ and FOXP3+ T cells as a mechanism of immune regulation in thin melanoma progression. However, elucidation of the significance of 
A

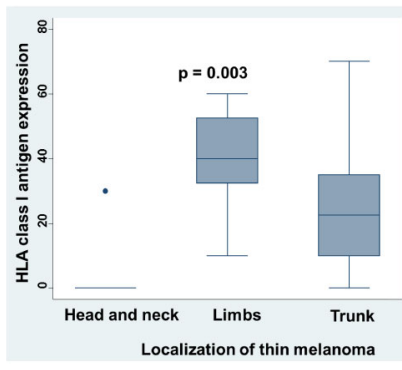

D

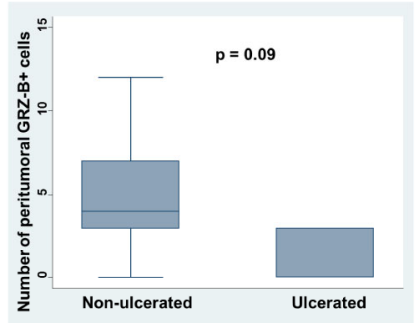

B

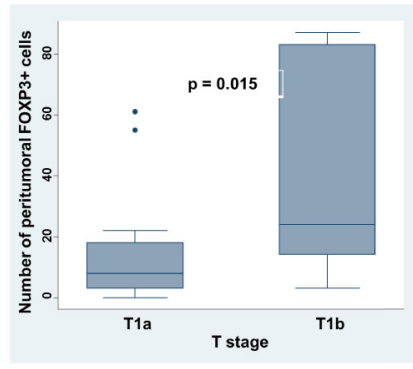

E

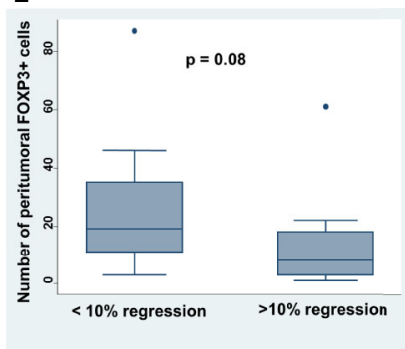

C
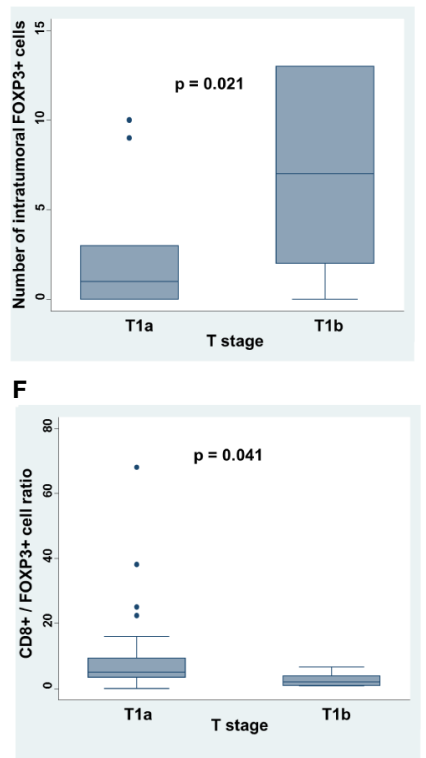

FIGURE 4 | Correlation between clinicopathological features and TIME characteristics in thin melanoma. (A) Site of primary thin melanoma was correlated to HLA class I antigen expression level by Kruskal-Wallis rank test. (B, C) T stage (sec. TNM, AJCC $8^{\text {th }}$ Edition) was correlated to the number of peritumoral and intratumoral FOXP3 + T cells by Mann-Whitney $U$ test. (D) Presence or absence of ulceration was correlated to the number of peritumoral GRZ-B+ T cells by Mann-Whitney $U$ test. (E) Number of peritumoral FOXP3+ T cells was correlated with presence or absence of regression at 10\% cut off of extension by Mann-Whitney $U$ test. (F) $T$ stage (sec. TNM, AJCC $8^{\text {th }}$ Edition) was correlated to CD8+/FOXP3+ T cell ratio by Mann-Whitney U test. On each box, the central mark is the median, the edges of the box are the $25^{\text {th }}$ and $75^{\text {th }}$ percentiles, the whiskers extend to the most extreme data points note considered outliers, and outliers are plotted individually. $p$ was considered significant if $<0.05$.

A

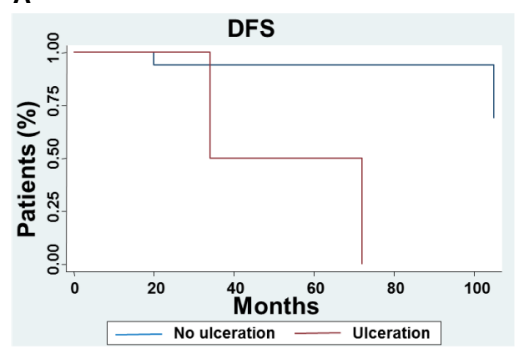

c

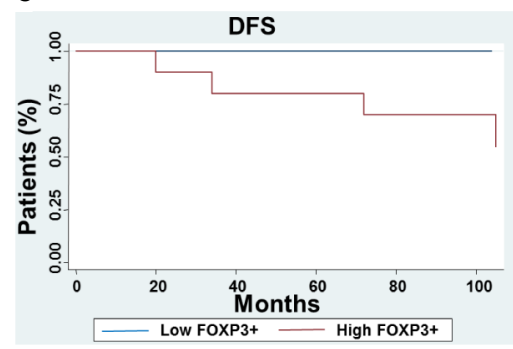

B

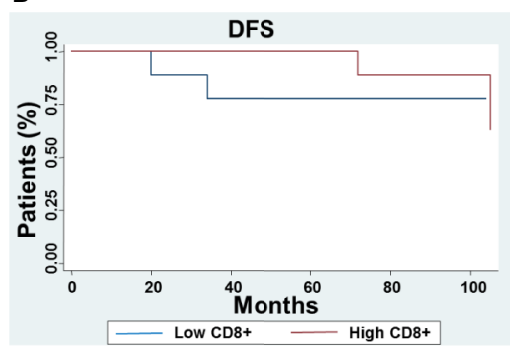

D

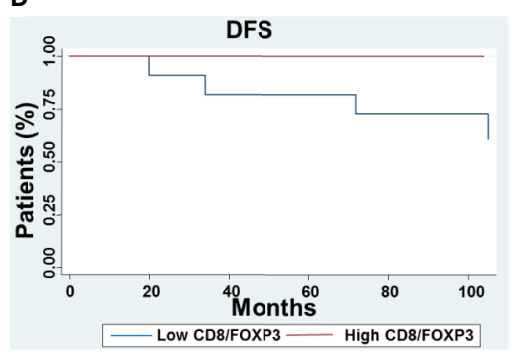

FIGURE 5 | Correlation between disease-free survival (DFS) and TIME characteristics in thin melanoma. The DFS of patients with lesions grouped based on ulceration (A), number of peritumoral CD8 + T cells (B), FOXP3 + cells (C) and CD8+/FOXP3 + T cell ratio (D) was compared using the Kaplan-Meier method. 
interactions between $\mathrm{CD} 8+\mathrm{T}$ cells and FOXP3 $+\mathrm{T}$ cells requires additional investigations.

In the present study we analyzed the CD8+ and FOXP3+ T cells localized along the stromal-tumor interface at tumor edge in dermis (peritumoral) and those completely surrounding the neoplastic cells (intratumoral). The number of CD8+ and FOXP3 $+\mathrm{T}$ cells were positively correlated with number of intratumoral CD8+ and FOXP3+ T cells, respectively. In some cases the number of intratumoral TILs was very low or negative. This was most likely caused by the low size of tumors analyzed. Nevertheless, in almost all cases, their number still correlated with the clinicopathological characteristics of tumors analyzed. Future studies in a larger patient cohort will be needed to validate their potential prognostic role in thin melanoma.

Besides CD8+ and FOXP3+ T cells, we also analysed the number of GRZ-B+ T cells as well as its correlation with clinicopathological characteristics of thin melanoma. We used GRZ-B expression as a readout for $\mathrm{CD} 8+\mathrm{T}$-cell cytotoxicity. However double immunofluorescent staining for CD8+ and GRZ-B+ cells demonstrated that GRZ-B did not co-localized with CD8 (Supplementary Data). Further studies are needed to characterize the subpopulation of GRZ-B+ cells. Their number showed a negative association, although non statistically significant, with presence of ulceration. The latter is a major unfavourable prognostic biomarker $(53,54)$. We also analyzed PD-L1 upregulation and HLA class I down-regulation on cancer cells since both represent two of the major tumor immune escape mechanisms $(17,19,20,23)$. HLA class I antigen and PD-L1 expression are known to play a key role in the host immune response to tumor antigens, since the former is crucial for processing tumor antigens and presentation of tumor antigen derived peptides to cognate $\mathrm{T}$ cells, while the latter inhibits T cell activation $(19,20,53,55)$. In our study no significant correlation was found between HLA class I antigen expression level and prognosis in thin melanoma, although HLA class I antigen expression is correlated with thin melanoma localization. Specifically, HLA class I antigen expression level was significantly higher in melanomas localized to limbs as compared to melanomas localized to head and neck or to trunk. The latter expressed the lowest levels of HLA class I antigens. It is well known that localization of primary melanoma is an important prognostic factor with the worst prognosis for melanoma localized to head and neck (56). On the other hand, PD-L1 expression level did not correlate to any of the clinicopathological characteristics of thin melanomas analyzed as well as to DFS. Conflicting data are reported about the prognostic role of PD-L1 expression in melanoma (19). These findings might reflect the lack of standardization of the IHC assay used to measure PD-L1 expression as well as the different characteristics of the PD-L1-specific antibodies utilized to in the assays. PD-L1 is also reported to be expressed on tumor associated macrophages in melanoma tumors (57). However, as we have already discussed above because of limited availability of tissue samples we were not able to analyze more biomarkers including those for tumor associated macrophages. Further studies are needed to investigate the role of tumor associated macrophages as well as the PD-L1 expression on tumor associated macrophages in thin melanomas.

\section{CONCLUSIONS}

In conclusion in this study we have shown that some of TIME characteristics may be a useful biomarker to improve thin melanoma prognosis. The low number of patients and tissue samples included in the analysis represents the major limitation of the present study. However, these findings, especially when independently validated in a larger patient cohort, have potential clinical significance since they can be used to define subgroups of thin melanoma patients who might benefit from different treatment modalities. Specifically, they can be useful to design novel clinical trials which utilize immune checkpoint inhibitorbased strategies for the treatment of thin melanoma patients with poor prognosis.

\section{DATA AVAILABILITY STATEMENT}

The raw data supporting the conclusions of this article will be made available by the authors, without undue reservation.

\section{ETHICS STATEMENT}

The studies involving human participants were reviewed and approved by ASL Napoli 3 sud Servizio Coordinamento Etico Campania Sud. The patients/participants provided their written informed consent to participate in this study.

\section{AUTHOR CONTRIBUTIONS}

Conception and design: FS, SF, SP. Development of methodology: FS, GS, SF. Acquisition of data: GS, AA, PZ. Analysis and interpretation of data: FS, GS, AA, PZ, JD. Writing, review, and/or revision of the manuscript: FS, LL, AM, SF. Administrative, technical, or material support (i.e., reporting or organizing data, constructing databases): GP, AC, AP. Study supervision: SP.

Other (contributed clinical and pathological material; discussed results and implications of findings): GB, SF, PZ, SP.

\section{FUNDING}

The work was supported by Ministero dell' Università e della Ricerca (Progetti di Rilevante Interesse Nazionale (PRIN), 2017, CODICE 2017PHRC8X_003) (to SP).

\section{ACKNOWLEDGMENTS}

The authors wish to gratefully acknowledge the patients for allowing us to publish this work.

\section{SUPPLEMENTARY MATERIAL}

The Supplementary Material for this article can be found online at: https://www.frontiersin.org/articles/10.3389/fimmu.2020. 561390/full\#supplementary-material 


\section{REFERENCES}

1. Ferlay J, Colombet M, Soerjomataram I, Mathers C, Parkin DM, Piñeros M, et al. Estimating the global cancer incidence and mortality in 2018: GLOBOCAN sources and methods. Int J Cancer (2019) 144:1941-53. doi: $10.1002 /$ ijc. 31937

2. Siegel RL, Miller KD, Jemal A. Cancer statistics, 2019. CA Cancer J Clin (2019) 69:7-34. doi: 10.3322/caac.21551

3. Balch CM, Gershenwald JE, Soong S-J, Thompson JF, Atkins MB, Byrd DR, et al. Final version of 2009 AJCC melanoma staging and classification. J Clin Oncol (2009) 27:6199-206. doi: 10.1200/JCO.2009.23.4799

4. Durham AB, Schwartz JL, Lowe L, Zhao L, Johnson AG, Harms KL, et al. The natural history of thin melanoma and the utility of sentinel lymph node biopsy. J Surg Oncol (2017) 116:1185-92. doi: 10.1002/jso.24765

5. Yonick DV, Ballo RM, Kahn E, Dahiya M, Yao K, Godellas C, et al. Predictors of positive sentinel lymph node in thin melanoma. Am J Surg (2011) 201:32427; discussion 327-28. doi: 10.1016/j.amjsurg.2010.09.011

6. Maurichi A, Miceli R, Camerini T, Mariani L, Patuzzo R, Ruggeri R, et al. Prediction of survival in patients with thin melanoma: results from a multiinstitution study. J Clin Oncol (2014) 32:2479-85. doi: 10.1200/JCO.2013.54.2340

7. Brandner JM, Haass NK. Melanoma's connections to the tumour microenvironment. Pathology (2013) 45:443-52. doi: 10.1097/PAT. 0b013e328363b3bd

8. Fischer GM, Vashisht Gopal YN, McQuade JL, Peng W, DeBerardinis RJ, Davies MA. Metabolic strategies of melanoma cells: Mechanisms, interactions with the tumor microenvironment, and therapeutic implications. Pigment Cell Melanoma Res (2018) 31:11-30. doi: 10.1111/pcmr.12661

9. Azimi F, Scolyer RA, Rumcheva P, Moncrieff M, Murali R, McCarthy SW, et al. Tumor-infiltrating lymphocyte grade is an independent predictor of sentinel lymph node status and survival in patients with cutaneous melanoma. J Clin Oncol (2012) 30:2678-83. doi: 10.1200/JCO.2011.37.8539

10. Donizy P, Kaczorowski M, Halon A, Leskiewicz M, Kozyra C, Matkowski R. Paucity of tumor-infiltrating lymphocytes is an unfavorable prognosticator and predicts lymph node metastases in cutaneous melanoma patients. Anticancer Res (2015) 35:351-8.

11. Fortes C, Mastroeni S, Mannooranparampil TJ, Passarelli F, Zappalà A, Annessi G, et al. Tumor-infiltrating lymphocytes predict cutaneous melanoma survival. Melanoma Res (2015) 25:306-11. doi: 10.1097/ CMR.0000000000000164

12. Park CK, Kim SK. Clinicopathological significance of intratumoral and peritumoral lymphocytes and lymphocyte score based on the histologic subtypes of cutaneous melanoma. Oncotarget (2017) 8:14759-69. doi: 10.18632/oncotarget.14736

13. Saldanha G, Flatman K, Teo KW. Bamford M. A Novel Numerical Scoring System for Melanoma Tumor-infiltrating Lymphocytes Has Better Prognostic Value Than Standard Scoring. Am J Surg Pathol (2017) 41:906-14. doi: 10.1097/PAS.0000000000000848

14. Thomas NE, Busam KJ, From L, Kricker A, Armstrong BK, Anton-Culver H, et al. Tumor-infiltrating lymphocyte grade in primary melanomas is independently associated with melanoma-specific survival in the population-based genes, environment and melanoma study. J Clin Oncol (2013) 31:4252-9. doi: 10.1200/JCO.2013.51.3002

15. Weiss SA, Han SW, Lui K, Tchack J, Shapiro R, Berman R, et al. Immunologic heterogeneity of tumor-infiltrating lymphocyte composition in primary melanoma. Hum Pathol (2016) 57:116-25. doi: 10.1016/j.humpath.2016.07.008

16. Eriksson H, Frohm-Nilsson M, Järås J, Kanter-Lewensohn L, Kjellman P, Månsson-Brahme E, et al. Prognostic factors in localized invasive primary cutaneous malignant melanoma: results of a large population-based study. $\mathrm{BrJ}$ Dermatol (2015) 172:175-86. doi: 10.1111/bjd.13171

17. De Panfilis G, Campanini N, Santini M, Mori G, Tognetti E, Maestri R, et al. Phase- and Stage-Related Proportions of T Cells Bearing the Transcription Factor FOXP3 Infiltrate Primary Melanoma. J Invest Dermatol (2008) 128:676-84. doi: 10.1038/sj.jid.5701046

18. Erdag G, Schaefer JT, Smolkin ME, Deacon DH, Shea SM, Dengel LT, et al. Immunotype and immunohistologic characteristics of tumor-infiltrating immune cells are associated with clinical outcome in metastatic melanoma. Cancer Res (2012) 72:1070-80. doi: 10.1158/0008-5472.CAN-11-3218
19. Frydenlund N, Mahalingam M. PD-L1 and immune escape: insights from melanoma and other lineage-unrelated malignancies. Hum Pathol (2017) 66:13-33. doi: 10.1016/j.humpath.2017.06.012

20. Hicklin DJ, Wang Z, Arienti F, Rivoltini L, Parmiani G, Ferrone S. beta2Microglobulin mutations, HLA class I antigen loss, and tumor progression in melanoma. J Clin Invest (1998) 101:2720-9. doi: 10.1172/JCI498

21. Kakavand H, Vilain RE, Wilmott JS, Burke H, Yearley JH, Thompson JF, et al. Tumor PD-L1 expression, immune cell correlates and PD-1+ lymphocytes in sentinel lymph node melanoma metastases. Mod Pathol (2015) 28:1535-44. doi: 10.1038/modpathol.2015.110

22. Obeid JM, Erdag G, Smolkin ME, Deacon DH, Patterson JW, Chen L, et al. PD-L1, PD-L2 and PD-1 expression in metastatic melanoma: Correlation with tumor-infiltrating immune cells and clinical outcome. Oncoimmunology (2016) 5:e1235107. doi: 10.1080/2162402X.2016.1235107

23. Park SL, Buzzai A, Rautela J, Hor JL, Hochheiser K, Effern M, et al. Tissueresident memory $\mathrm{CD} 8+\mathrm{T}$ cells promote melanoma-immune equilibrium in skin. Nature (2019) 565:366-71. doi: 10.1038/s41586-018-0812-9

24. Requena C, Botella-Estrada R, Traves V, Nagore E, Almenar S, Guillén C. Problems in Defining Melanoma Regression and Prognostic Implication. Actas Dermo-Sifiliográficas (English Edition) (2009) 100:759-66. doi: 10.1016/S1578-2190(09)70171-4

25. Smoller BR. Histologic criteria for diagnosing primary cutaneous malignant melanoma. Mod Pathol (2006) 19 (Suppl 2):S34-40. doi: 10.1038/ modpathol. 3800508

26. Zurac S, Negroiu G, Petrescu S, Andrei R, Tebeica T, Popp C, et al. Spectrum of morphologic alterations of regression in cutaneous melanoma-potential for improving disease prognosis. Rom J Intern Med (2012) 50:145-53.

27. Osella-Abate S, Conti L, Annaratone L, Senetta R, Bertero L, Licciardello M, et al. Phenotypic characterisation of immune cells associated with histological regression in cutaneous melanoma. Pathology (2019) 51:487-93. doi: 10.1016/ j.pathol.2019.04.001

28. Stam NJ, Spits H, Ploegh HL. Monoclonal antibodies raised against denatured HLA-B locus heavy chains permit biochemical characterization of certain HLA-C locus products. J Immunol (1986) 137:2299-306.

29. Sernee MF, Ploegh HL, Schust DJ. Why certain antibodies cross-react with HLA-A and HLA-G: epitope mapping of two common MHC class I reagents. Mol Immunol (1998) 35:177-88. doi: 10.1016/s0161-5890(98)00026-1

30. Perosa F, Luccarelli G, Prete M, Favoino E, Ferrone S, Dammacco F. Beta 2microglobulin-free HLA class I heavy chain epitope mimicry by monoclonal antibody HC-10-specific peptide. J Immunol (2003) 171:1918-26. doi: 10.4049/jimmunol.171.4.1918

31. Sabbatino F, Villani V, Yearley JH, Deshpande V, Cai L, Konstantinidis IT, et al. PD-L1 and HLA Class I Antigen Expression and Clinical Course of the Disease in Intrahepatic Cholangiocarcinoma. Clin Cancer Res (2016) 22:4708. doi: 10.1158/1078-0432.CCR-15-0715

32. Sabbatino F, Marra A, Liguori L, Scognamiglio G, Fusciello C, Botti G, et al. Resistance to anti-PD-1-based immunotherapy in basal cell carcinoma: a case report and review of the literature. J Immunother Cancer (2018) 6:126. doi: 10.1186/s40425-018-0439-2

33. Ogino T, Bandoh N, Hayashi T, Miyokawa N, Harabuchi Y, Ferrone S. Association of Tapasin and HLA Class I Antigen Down-Regulation in Primary Maxillary Sinus Squamous Cell Carcinoma Lesions with Reduced Survival of Patients. Clin Cancer Res (2003) 9:4043-51.

34. Balch CM, Wilkerson JA, Murad TM, Soong SJ, Ingalls AL, Maddox WA. The prognostic significance of ulceration of cutaneous melanoma. Cancer (1980) 45:3012-7. doi: 10.1002/1097-0142(19800615)45:12<3012::aid-cncr282045 $1223>3.0 . c 0 ; 2-\mathrm{o}$

35. Shen S, Wolfe R, McLean CA, Haskett M, Kelly JW. Characteristics and associations of high-mitotic-rate melanoma. JAMA Dermatol (2014) 150:1048-55. doi: 10.1001/jamadermatol.2014.635

36. Dessinioti C, Dimou N, Geller AC, Stergiopoulou A, Lo S, Keim U, et al. Distinct clinicopathological and prognostic features of thin nodular primary melanomas: an international study from 17 centers. J Natl Cancer Inst (2019) 111:1314-22. doi: 10.1093/jnci/djz034

37. Lundgren S, Fagerström-Vahman H, Zhang C, Ben-Dror L, Mardinoglu A, Uhlen $\mathrm{M}$, et al. Discovery of KIRREL as a biomarker for prognostic stratification of patients with thin melanoma. Biomark Res (2019) 7:1. doi: $10.1186 / \mathrm{s} 40364-018-0153-8$ 
38. Chen Y-P, Zhang Y, Lv J-W, Li Y-Q, Wang Y-Q, He Q-M, et al. Genomic Analysis of Tumor Microenvironment Immune Types across 14 Solid Cancer Types: Immunotherapeutic Implications. Theranostics (2017) 7:3585-94. doi: $10.7150 /$ thno. 21471

39. Marzagalli M, Ebelt ND, Manuel ER. Unraveling the crosstalk between melanoma and immune cells in the tumor microenvironment. Semin Cancer Biol (2019) 59:236-50. doi: 10.1016/j.semcancer.2019.08.002

40. Wieder T, Brenner E, Braumüller H, Röcken M. Immunotherapy of melanoma: efficacy and mode of action. J Dtsch Dermatol Ges (2016) 14:28-37. doi: 10.1111/ddg.12819

41. Eggermont AMM, Blank CU, Mandala M, Long GV, Atkinson V, Dalle S, et al. Adjuvant Pembrolizumab versus Placebo in Resected Stage III Melanoma. N Engl J Med (2018) 378:1789-801. doi: 10.1056/NEJMoa1802357

42. Larkin J, Chiarion-Sileni V, Gonzalez R, Grob JJ, Cowey CL, Lao CD, et al. Combined Nivolumab and Ipilimumab or Monotherapy in Untreated Melanoma. N Engl J Med (2015) 373:23-34. doi: 10.1056/NEJMoa1504030

43. Robert C, Long GV, Brady B, Dutriaux C, Maio M, Mortier L, et al. Nivolumab in previously untreated melanoma without BRAF mutation. $N$ Engl J Med (2015) 372:320-30. doi: 10.1056/NEJMoa1412082

44. Robert C, Thomas L, Bondarenko I, O’Day S, Weber J, Garbe C, et al. Ipilimumab plus dacarbazine for previously untreated metastatic melanoma. N Engl J Med (2011) 364:2517-26. doi: 10.1056/NEJMoa1104621

45. Weber J, Mandala M, Del Vecchio M, Gogas HJ, Arance AM, Cowey CL, et al. Adjuvant Nivolumab versus Ipilimumab in Resected Stage III or IV Melanoma. N Engl J Med (2017) 377:1824-35. doi: 10.1056/NEJMoa1709030

46. Clemente CG, Mihm MC, Bufalino R, Zurrida S, Collini P, Cascinelli N. Prognostic value of tumor infiltrating lymphocytes in the vertical growth phase of primary cutaneous melanoma. Cancer (1996) 77:1303-10. doi: 10.1002/(SICI) 1097-0142(19960401)77:7<1303::AID-CNCR12>3.0.CO;2-5

47. van Houdt IS, Sluijter BJR, Moesbergen LM, Vos WM, de Gruijl TD, Molenkamp BG, et al. Favorable outcome in clinically stage II melanoma patients is associated with the presence of activated tumor infiltrating Tlymphocytes and preserved MHC class I antigen expression. Int J Cancer (2008) 123:609-15. doi: 10.1002/ijc.23543

48. Hillen F, Baeten CIM, van de Winkel A, Creytens D, van der Schaft DWJ, Winnepenninckx V, et al. Leukocyte infiltration and tumor cell plasticity are parameters of aggressiveness in primary cutaneous melanoma. Cancer Immunol Immunother (2008) 57:97-106. doi: 10.1007/s00262-007-0353-9

49. Fu Q, Chen N, Ge C, Li R, Li Z, Zeng B, et al. Prognostic value of tumorinfiltrating lymphocytes in melanoma: a systematic review and meta-analysis. Oncoimmunology (2019) 8:1593806. doi: 10.1080/2162402X.2019.1593806
50. Miracco C, Mourmouras V, Biagioli M, Rubegni P, Mannucci S, Monciatti I et al. Utility of tumour-infiltrating $\mathrm{CD} 25+\mathrm{FOXP} 3+$ regulatory $\mathrm{T}$ cell evaluation in predicting local recurrence in vertical growth phase cutaneous melanoma. Oncol Rep (2007) 18:1115-22. doi: 10.3892/or.18.5.1115

51. Durgeau A, Virk Y, Corgnac S, Mami-Chouaib F. Utility of tumourinfiltrating $\mathrm{CD} 25+\mathrm{FOXP} 3+$ regulatory $\mathrm{T}$ cell evaluation in predicting local recurrence in vertical growth phase cutaneous melanoma. Front Immunol (2018) 9:14. doi: 10.3389/fimmu.2018.00014

52. Sade-Feldman M, Yizhak K, Bjorgaard SL, Ray JP, de Boer CG, Jenkins RW, et al. Defining $\mathrm{T}$ Cell States Associated with Response to Checkpoint Immunotherapy in Melanoma. Cell (2018) 175:998-1013.e20. doi: 10.1016/ j.cell.2018.10.038

53. Mahmoud F, Shields B, Makhoul I, Avaritt N, Wong HK, Hutchins LF, et al. Immune surveillance in melanoma: From immune attack to melanoma escape and even counterattack. Cancer Biol Ther (2017) 18:451-69. doi: 10.1080/ 15384047.2017.1323596

54. Mascaro JM, Castro J, Castel T, Lecha M, Gratacos R, Mascaro JM. Why do melanomas ulcerate? J Cutan Pathol (1984) 11:269-73. doi: 10.1111/j.16000560.1984.tb00377.x

55. Hino R, Kabashima K, Kato Y, Yagi H, Nakamura M, Honjo T, et al. Tumor cell expression of programmed cell death-1 ligand 1 is a prognostic factor for malignant melanoma. Cancer (2010) 116:1757-66. doi: 10.1002/cncr.24899

56. Magnus K. Prognosis in malignant melanoma of the skin. Significance of stage of disease, anatomical site, sex, age and period of diagnosis. Cancer (1977) 40:389-97. doi: 10.1002/1097-0142(197707)40:1<389::aid-cncr2820400155>3.0.co;2-i

57. Madonna G, Ballesteros-Merino C, Feng Z, Bifulco C, Capone M, Giannarelli $\mathrm{D}$, et al. PD-L1 expression with immune-infiltrate evaluation and outcome prediction in melanoma patients treated with ipilimumab. Oncoimmunology (2018) 7:e1405206. doi: 10.1080/2162402X.2017.1405206

Conflict of Interest: The authors declare that the research was conducted in the absence of any commercial or financial relationships that could be construed as a potential conflict of interest.

Copyright (C) 2020 Sabbatino, Scognamiglio, Liguori, Marra, Anniciello, Polcaro, Dal Col, Caputo, Peluso, Botti, Zeppa, Ferrone and Pepe. This is an open-access article distributed under the terms of the Creative Commons Attribution License (CC BY). The use, distribution or reproduction in other forums is permitted, provided the original author(s) and the copyright owner(s) are credited and that the original publication in this journal is cited, in accordance with accepted academic practice. No use, distribution or reproduction is permitted which does not comply with these terms. 